\title{
Effect on the mechanical properties of sheet metals after the use of drawbeads in deep drawing
}

\author{
Harald Schmid $^{1, *}$ and Marion Merklein ${ }^{1}$ \\ ${ }^{1}$ Institute of Manufacturing Technology, Friedrich-Alexander-Universität Erlangen-Nürnberg, Egerlandstraße 11-13, 91058 Erlangen, \\ Germany
}

\begin{abstract}
The use of modern and more complex materials leads to a need for detailed knowledge and controlling of the material flow. Next to the blank holder force or the lubrication system, drawbeads are nowadays one common way to bring serial forming processes under control. Although drawbeads are already well investigated regarding their retention forces, the effect on the resulting mechanical properties after a drawbead passage is not analysed in detail yet. This work will show the influence of a common drawbead geometry used in forming processes on typical mechanical properties of sheet metal. Therefore, two different sheet metal materials are preloaded in a modified strip drawing test with industrial used drawbead geometry. In testing, three different pressure levels between 2.5 MPa and 7.5 MPa and three levels of drawing speed between $10 \mathrm{~mm} / \mathrm{s}$ and $50 \mathrm{~mm} / \mathrm{s}$ are combined to nine variations which will be examined. Afterwards, specimens are cut out by a laser cutting machine of the drawn strips. Those already preloaded and deformed specimens are then tested under standard conditions with the use of an optical measurement system. The results like tensile strength or elongation at fracture are compared to the initial state and each other and discussed with consideration of pressure and speed levels to work out the main effects. Those results are a contribution for the optimization of deep drawing simulations of parts including drawbeads or to evaluate the influence of drawbeads on forming processes to specify or even expand process limitations.
\end{abstract}

Keywords: Deep drawing, Hardening, Sheet metal

\section{Introduction}

Deep drawn parts are more complex in geometry and material these days than in the past [1]. This requires the accurate knowledge and prediction of the material flow to control it and to achieve satisfying product quality. While modifications of the blank holder force or the lubrication system are options to control forming processes, drawbeads are also a popular way to improve the material flow. Drawbeads are already examined in detail regarding retention forces but not when considering modified mechanical properties of the sheet metal after a drawbead passage. This causes the necessity for a more detailed investigation of the impact of drawbeads on the used sheet material itself. At the moment, a lot of conventional steel materials in the automotive industry are replaced with high strength steel for the reason of light weight design, according to Mohrbacher et al. [2]. Because of the high formability and their high strength, the sheet thickness and therefore the overall weight can be reduced, what is also described by Bleck and Ratte in [3].

In the past, different authors have already investigated drawbeads and their effects on the forming process. Liu et al. could already successfully predict in [4] the forming and springback behaviour of sheet material undergoing multiple bending-unbending cycles, as they appear in a drawbead. A FE simulation combined with a nonlinear isotropic / kinematic hardening model shows almost the same results compared to the conducted experiments. According to their findings, the predicted results are highly influenced by the used hardening model and the results present a decreasing accuracy with more bending-unbending cycles compared to the experimental data. That's another reason, why sheet metal hardening after drawbeads should be examined. In [5], the hardening of sheet metal was examined for two different levels of blank holder pressure and in three layers over the thickness. It could be demonstrated, that a drawbead leads to different hardening levels in the sheet layers and in drawing direction after the passage. Also, results from a modified strip drawing test with a drawbead geometry are compared to results from a deep drawing process. In addition, in [6] the influence of drawbeads on material hardening was also investigated on the upper and lower side in drawing direction. Additionally, the measured strain development was correlated with the hardening behaviour and an overall hardening as well as a rising accumulated strain was described.

Halkaci et al. show in [7], that a deep drawing process is changed with drawbeads and improves the limiting drawing ratio by up to $10 \%$. This also indicates a shift in mechanical properties for the use of drawbeads. Samuel develops a numerical model in [8] to calculate forces and stresses during a drawbead passage and compares these findings with his experimental data. A new material model is used, which is also based on the strain hardening exponent $\mathrm{n}$ from tensile tests. The numerical results are found in a good agreement with the experimental data in between $8 \%$ deviation. It is also observed, that the drawbead geometry and friction 
coefficient highly affect the retention and pressure forces for the calculations in a process with drawbeads. Looking on the used materials DC04 and DP800, also some investigations have been conducted regarding the hardening behaviour. Silvestre et al. [9] investigated different hardening behaviour of different steel grades. It was shown, that mild steels like DC04 are presenting a cyclic hardening behaviour when they are loaded and reverse loaded again and again. In comparison, the advanced high strength steels like the investigated DP800 show cyclic softening behaviour. Also, the mild steel was increasing its yield strength with every cycle, while the advanced high strength steels showed a constant yield strength value with every cycle. This can be seen as a saturation and a stable microstructure, according to [9]. Finally, the two used steel grades already show a different hardening behaviour, what obviously also has effects when considering the sheet metal after a drawbead passage. Additionally, Schreijäg [10] examined in 2013, that macroscopic forming conditions of DC04 mainly depend on the anisotropy of the texture of the used sheet metal. Connecting this with the deep drawing process through drawbeads, it could be possible to achieve different mechanical properties after a drawbead passage, depending on the rolling direction.

All presented findings can be interpreted as a note for significant changes in mechanical properties after a drawbead passage. Such a shift can lead to the incorrect determination of material models and poor numerical calculations what finally leads to bad forming results. This makes further and more detailed investigations of drawbead processed parts necessary. Especially standardized material characterization techniques seem to be suitable to compare results of preloaded parts to their initial state. Within these investigations, the uniaxial tensile test is used to investigate the influence of drawbeads on sheet metal parts. The tensile test is very useful, as it is an international standardized material test. Also, it is possible to determine well known and meaningful parameters like the tensile strength TS, the yield strength YS, the uniform strain $\varepsilon_{\mathrm{u}}$ or the elongation at break $\varepsilon_{f}$. At the moment, there are insufficient investigations about the influence of different process parameters on the material characteristics. This testing will help to determine the behaviour of different sheet metal materials under varying conditions in the drawbead passage and to improve the deep drawing process itself.

\section{Materials}

Because of their use in the automotive industry, conventional steel and a high-strength steel will be examined after a drawbead passage. Therefore, DC04, a kind of mild steel, is used very commonly in deep drawing processes. Also, an advanced high strength steel HCT780X, also called DP800, will be observed as a modern lightweight-material. It is often used in the automotive industry in the last years. The mild steel DC04 offers a high formability in forming processes and is used here in an initial thickness of $t_{0}=1.0 \mathrm{~mm}$. The initial tensile strength is $\mathrm{TS}=314.4 \mathrm{MPa}$, the yield strength YS $=162.1 \mathrm{MPa}$, the uniform elongation $\varepsilon_{\mathrm{u}}=25.9 \%$ and the fracture strain $\varepsilon_{\mathrm{f}}=44.2 \%$. DP800 presents a significant higher tensile strength of $\mathrm{TS}=817.9 \mathrm{MPa}$ and the yield strength $\mathrm{YS}=516.1 \mathrm{MPa}$. The uniform elongation of DP800 is about the half of DC04 and amounts with $\varepsilon_{\mathrm{u}}=12.9 \%$ while the fracture strain is about $\varepsilon_{\mathrm{f}}=17.4 \%$. The strain hardening exponent of DP800 is about $\mathrm{n}_{\mathrm{DP} 800}=0.27$ while DC04 has an exponent of $\mathrm{n}_{\mathrm{DC} 04}=0.16$, what is about the half. These material parameters in the initial state will be used in this work to quantify the changes of the material parameters after a drawbead.

\section{Experimental setup}

First of all, the sheet metal strips with a size of $700 \times 50 \mathrm{~mm}^{2}$ need to pass the drawbead passage where they are preloaded. Therefore, a modified strip drawing test is used, that is also described in [6] and shown in Figure 1. The used drawbead geometry is built according to the Numisheet 2008 benchmark and has a peak radius of $6.5 \mathrm{~mm}$ and a height of $3.6 \mathrm{~mm}$ with running-in and running-out radii of $2.5 \mathrm{~mm}$. The drawbead tool is built into a strip drawing test machine, as can also be seen in Figure 1. Also, the schematic process is illustrated. After being lubricated with deep-drawing oil Multidraw KTL N 16 (Zeller + Gmelin GmbH), the metal strips are subsequently drawn through the drawbead. This is done with varying velocities of $\mathrm{v}=10 \mathrm{~mm} / \mathrm{s}, 30 \mathrm{~mm} / \mathrm{s}$ and 50 $\mathrm{mm} / \mathrm{s}$ while the blank holder pressure is varied between $\mathrm{p}_{\mathrm{N}}=2.5 \mathrm{MPa}$, 5.0 $\mathrm{MPa}$ and $7.5 \mathrm{MPa}$. During this process, the velocity $\mathrm{v}$ and the normal pressure $\mathrm{p}_{\mathrm{N}}$ are controlled automatically and kept constant. After that, A50 tensile test specimens are laser cut out of the preloaded and deformed metal strips. Therefore, the strips have to be fixed on the laser machine bed because of their deformation to cut the correct specimen geometry. The preloading as well as the cut out is executed in $0^{\circ}$ to the rolling direction. Specimens in $45^{\circ}$ or $90^{\circ}$ to the rolling direction cannot be extracted after preloading because of the strips' geometric boundaries.

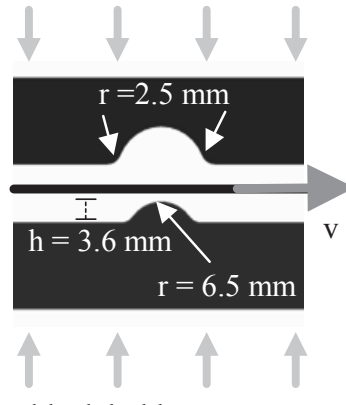

blank holder pressure $\mathrm{p}_{\mathrm{N}}$

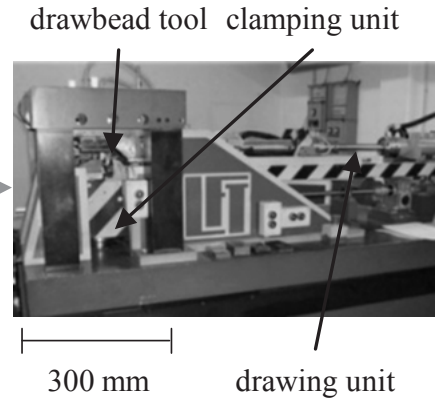

b)
Figure 1. Strip drawing test with drawbead in schematic process illustration (a) and used test bed (b)

Finally, five specimens were tensile tested for every variation $(\mathrm{n}=5)$ on a universal testing machine $\mathrm{Z100}$ (Zwick GmbH \& Co. KG) based on DIN EN ISO 6892 
and by using the optical measurement system ARAMIS (GOM GmbH). The evaluation of the elongation was averaged for every specimen over the measurement area with a length of $1_{0}=50 \mathrm{~mm}$. The process and methodology is also presented in Figure 2.

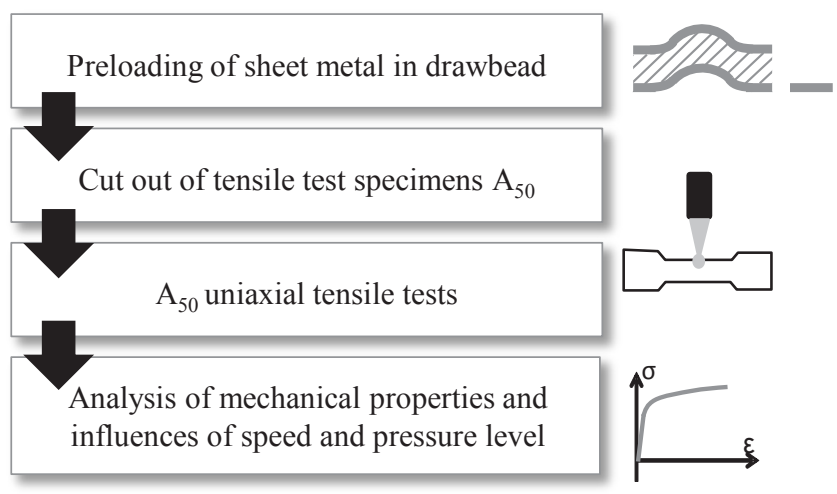

Figure 2. Methodology used for tensile test examination

Because of their importance for the deep drawing process, the influence of the blank holder pressure $p_{N}$ and the velocity $\mathrm{v}$ in a drawbead are examined. The results are pointed out in the next chapter.

\section{Results}

After drawing the metal strips through the drawbead, every metal strip has a different thickness depending on the material and the varied parameters in this process. This is considered in the tensile tests, which are performed for the analysis of the stresses. In Figure 3, the thickness results for the preloaded strips are presented. In general, the thinning is more obvious for DC04 compared to DP800. Also, the increase in pressure leads to thinner sheet metal strips after a drawbead. The effect of the velocity on the sheet thickness $t_{1}$ at constant pressure $p_{N}$ is in between the standard deviation and therefore not significant. For the highest pressure of $\mathrm{p}_{\mathrm{N}}=7.5 \mathrm{MPa}$, the material DP800 has a thickness of $\mathrm{t}_{1}=$ $0.95 \mathrm{~mm}$ and for DC04 of $\mathrm{t}_{1}=0.9 \mathrm{~mm}$. According to the thickness reduction results in Figure 3, changes already become visible and trends can be indicated.

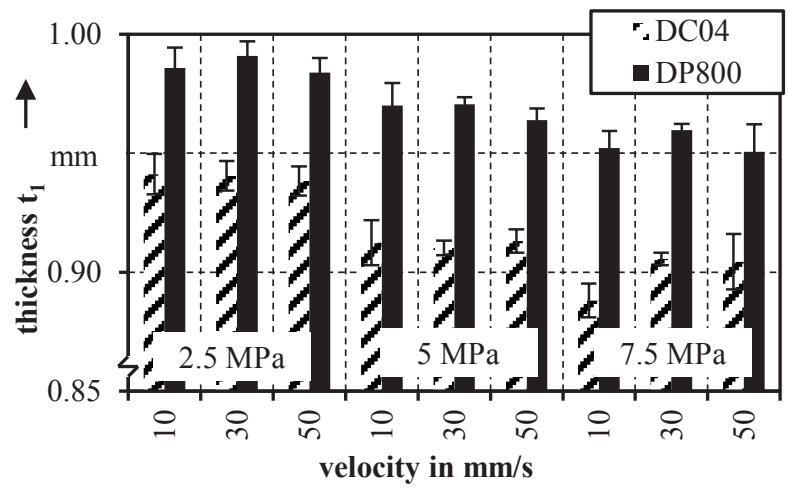

Figure 3. Strip thickness after drawbead for tested variations

For more detailed results, further experimental investigations under varying parameters have been conducted. The influence of the velocity and the blank holder pressure in the strip drawing test with drawbead is analysed in the tensile test setup. To get an impression and overlook of the changes in the material characteristics, a true stress-true strain diagram of both materials is drawn in Figure 4. It shows the curves for DC04 and DP800 in the initial state and after a drawbead preloading for the test variation of $\mathrm{v}=30 \mathrm{~mm} / \mathrm{s}$ and the blank holder pressure $\mathrm{p}_{\mathrm{N}}=5 \mathrm{MPa}$.

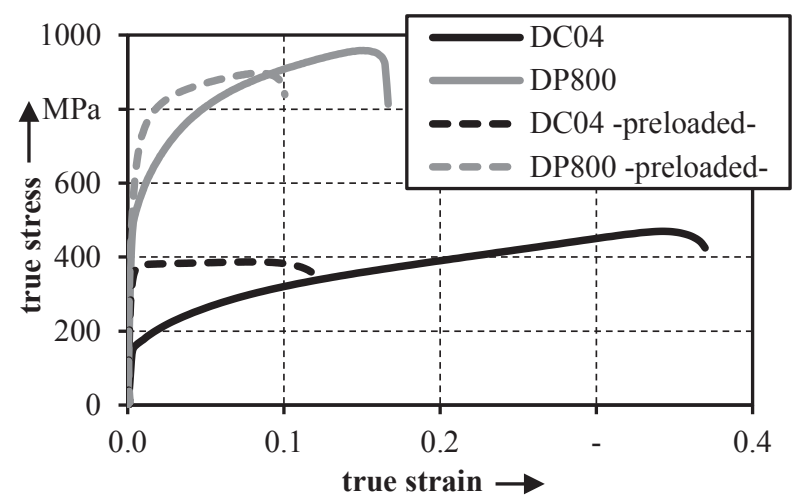

Figure 4. True Stress- true strain diagram of initial and preloaded DC04 and DP800 $\left(\mathrm{p}_{\mathrm{N}}=5 \mathrm{MPa}, \mathrm{v}=30 \mathrm{~mm} / \mathrm{s}\right)$

It can be observed, that for both materials a significant change is visible. In Figure 4, the fracture strain is clearly smaller for the preloaded materials. Also, the maximum of the true stress changes significantly. These curves also indicate the need for further, detailed comparison of the standard material parameters to quantify the occurred changes. In Figure 5, the changes of a varying velocity and a constant blank holder pressure of $\mathrm{p}_{\mathrm{N}}=5 \mathrm{MPa}$ are shown for a better comparison between the different variations and the two materials.

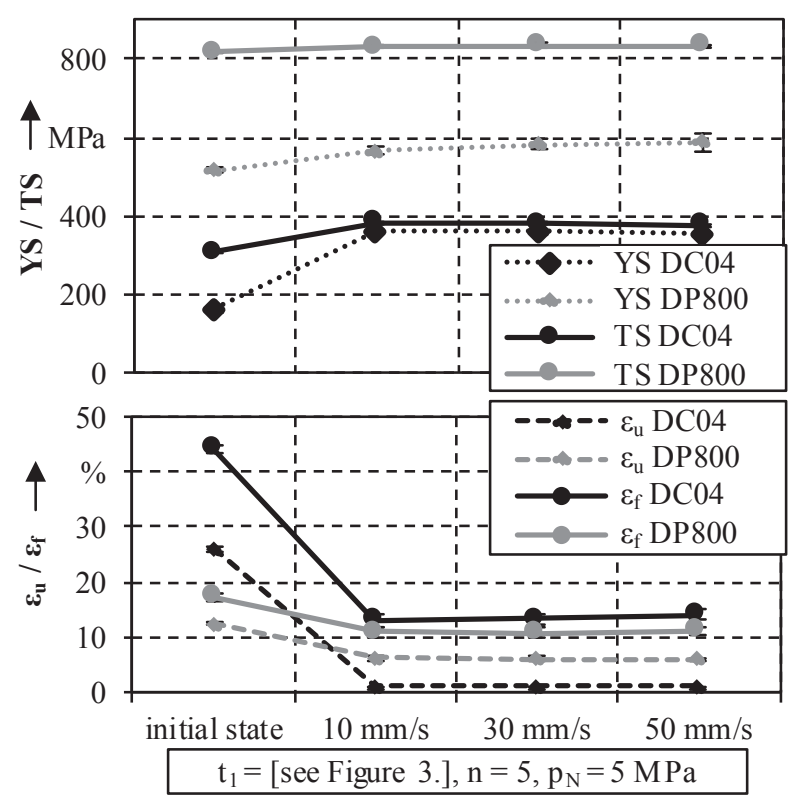

Figure 5. Material parameters after drawbead passage for the variation of the drawing velocity $\mathrm{v}$ and constant pressure $\mathrm{p}_{\mathrm{N}}$ 
The tensile strength TS for DC04, in black, is increased by about $100 \mathrm{MPa}$, while the yield strength YS is increased by nearly $200 \mathrm{MPa}$. The uniform elongation $\varepsilon_{\mathrm{u}}$ decreases to only $1 \%$ while the fracture strain also decreases from $45 \%$ to about $15 \%$. For DP800 in grey, there is only a slight increase of the tensile strength TS and yield strength YS visible. The fracture strain is divided in half, what can also be said for the uniform elongation. For both materials, there is no big difference in between the curves when varying the velocity. The difference for the materials is in between the standard deviation, so the variation of the velocity in between $\mathrm{v}=$ $10-50 \mathrm{~mm} / \mathrm{s}$ most likely does not have an impact on the material itself. At least the parameters do not change significantly compared to the other preloaded specimens.

Analysing the variation of the blank holder pressure $\mathrm{p}_{\mathrm{N}}$ with a constant velocity of $\mathrm{v}=50 \mathrm{~mm} / \mathrm{s}$, the results are more manifold. As it can be seen in Figure 6 for DC04, there is a visible difference between the varied blank holder pressure levels. The tensile strength rises with more pressure what also takes effect for YS. This can also be seen in Figure 7. The uniform elongation and the fracture strain are decreasing with higher pressure levels. The values for $5 \mathrm{MPa}$ and $7.5 \mathrm{MPa}$ are only demonstrating small changes compared to the gradient from 2.5 $\mathrm{MPa}$ to $5 \mathrm{MPa}$. Considering the diagram in Figure 6 for DP800, the same findings can be observed. Although the tensile strength does not increase in the same amount compared to DC04, a higher pressure level also provides higher tensile strength levels. Looking on the strain in the preloaded specimens, a decrease is visible. By rising the pressure level from $2.5 \mathrm{MPa}$ to 5 $\mathrm{MPa}$ and further on to $7.5 \mathrm{MPa}$, the fracture strain and the uniform elongation are clearly minimized.

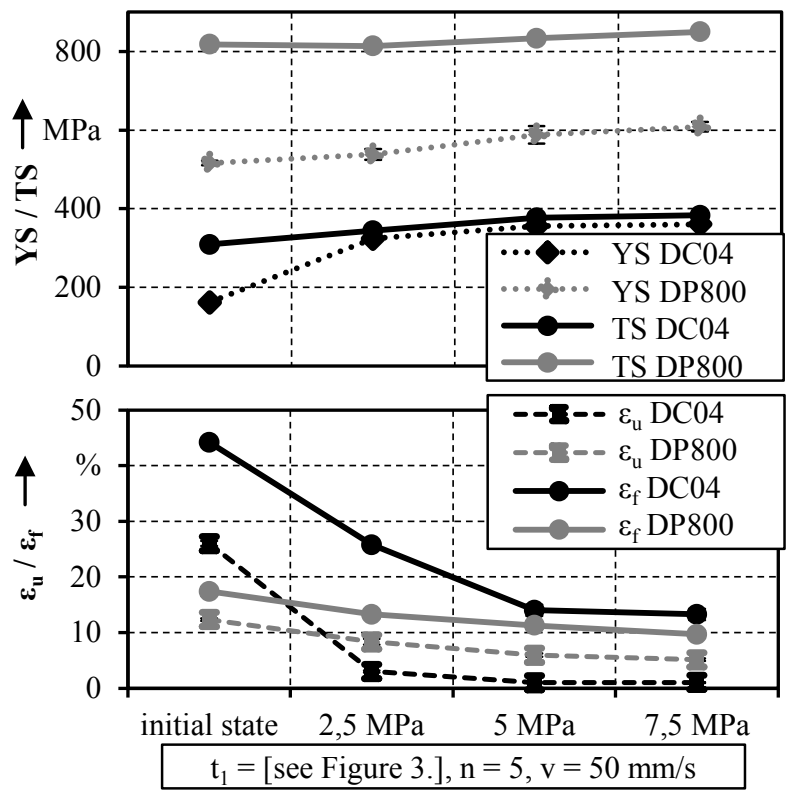

Figure 6. Material parameters after drawbead passage for the variation of the blank holder pressure $\mathrm{p}_{\mathrm{N}}$ and the constant drawing velocity $\mathrm{v}$

Compared to each other, DC04 shows a higher increase of the tensile strength while DP800 does not have a high rise. The uniform elongation is also minimized roughly for DC04 while value for DP800 does not decrease in the same amount. Because the two tested materials show a different behaviour in the tensile tests, it is necessary to analyse them by using specific values and to compare them respecting the initial state of the parameters.

\section{Discussion}

For the comparison and detailed discussion of the conducted tensile tests, the tensile strength and the fracture strain are chosen to be investigated in detail. All in all, the parameters of the variations have a standard deviation of about maximum $7 \%$ compared to the average value. This deviation was examined with a number of specimens of $n=5$. The tensile strength TS provides a good overview of the maximum tolerable stresses and is therefore a parameter describing maximum tolerable loads. The fracture strain is used as a value for the ultimate plastic strain to failure, what is a descriptive value. It is the parameter describing the material failure regarding the strain and not only the stresses.

The analysed parameters are set in relation to their initial state and the increase or decrease is given in percent. Also, the standard deviation is calculated with five specimens tested and shown in Figure 7. For a better overlook, the results for both materials are drawn into one diagram considering the variation of the tensile strength TS in Figure 7 and the fracture strain $\varepsilon_{\mathrm{f}}$ in Figure 8. In general, the tensile strength for DC04 is increased nearly up to $25 \%$ for the variation $\mathrm{p}_{\mathrm{N}}=7.5 \mathrm{MPa}$ and $\mathrm{v}=50 \mathrm{~mm} / \mathrm{s}$, while for the same setting the fracture strain is decreased by over $70 \%$.

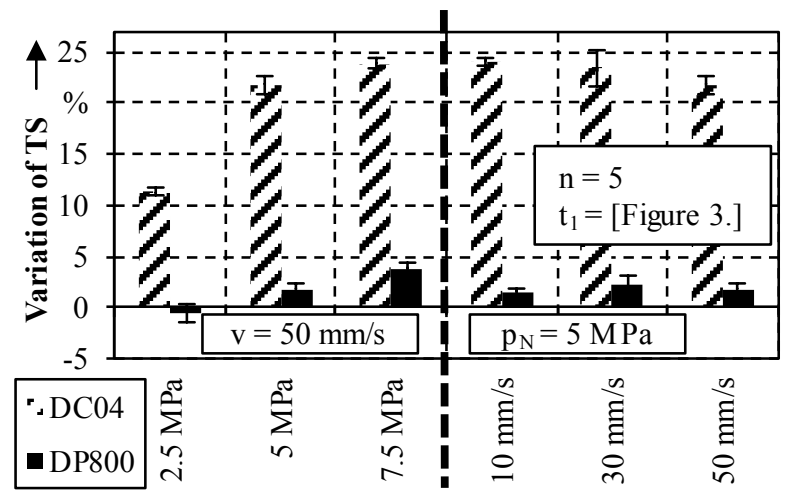

Figure 7. Modification of the tensile strength TS in tensile tests after preloading in a drawbead passage

On the first hand, it is visible that the increase in tensile strength TS is way higher for DC04 compared to DP800. As said before, the tensile strength for DC04 increases nearly up to $25 \%$, while DP 800 's rises only by about $4 \%$. One variation of DP800 $\left(\mathrm{p}_{\mathrm{N}}=2.5 \mathrm{MPa}, \mathrm{v}=\right.$ $50 \mathrm{~mm} / \mathrm{s}$ ) even shows a very small decrease. In practical use, this can likely be seen as no influence on TS at all.

It is visible, that with an increase of the normal pressure $p_{\mathrm{N}}$ in the strip drawing test, the value for the tensile strength TS after preloading is increasing. For the 
velocity of $\mathrm{v}=50 \mathrm{~mm} / \mathrm{s}$, the influence of the normal pressure $\mathrm{p}_{\mathrm{N}}$ increases the level of TS from about $11 \%$ at $\mathrm{p}_{\mathrm{N}}=2.5 \mathrm{MPa}$ over to about $21 \%$ at $\mathrm{p}_{\mathrm{N}}=5 \mathrm{MPa}$ up to about $25 \%$ at a blank holder pressure of $7.5 \mathrm{MPa}$. The small difference for the tensile strength TS between $\mathrm{p}_{\mathrm{N}}=5$ and $7.5 \mathrm{MPa}$ indicates that the material is saturated by plastic deformation. Regarding the DC04 results for varying the velocity, there is a very small decrease in the yield strength what could also be called a trend. The standard deviations of TS with the influence of the velocity are overlapping, what means there is no significant difference.

When looking at DP800 in Figure 7, the increase of TS is only $4 \%$ and somewhat lower compared to DC04. Indeed, one can also detect an increase in the tensile strength TS for a rising of the pressure $\mathrm{p}_{\mathrm{N}}$, but only up to $4 \%$ and not to $25 \%$ like for DC04. For the variation of the velocity $\mathrm{v}$, there are no significant differences in the development of TS for DP800. For Figure 7, it can be summarised for the investigated boundaries, which a higher blank holder pressure $\mathrm{p}_{\mathrm{N}}$ leads to higher values for TS with maximum up to $25 \%$ for DC0 4 and $4 \%$ for DP800. The velocity between $\mathrm{v}=10-50 \mathrm{~mm} / \mathrm{s}$ tends to have no influence, because TS does not show any significant shift for these variations. DP800 all in all shows a lower level of residual formability considering the tensile strength compared to DC04. After considering the changes in the applicable stresses, the effect of the drawbead on the maximum bearable strain in the tensile test will be considered. In Figure 8, the influence of the parameters $\mathrm{v}$ and $\mathrm{p}_{\mathrm{N}}$ on the fracture strain $\varepsilon_{\mathrm{f}}$ is given.

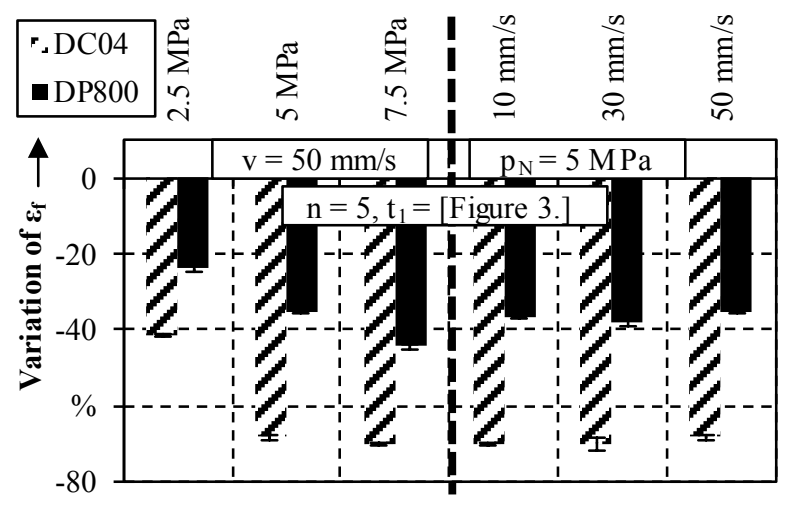

Figure 8. Percentage modification of the fracture strain in tensile tests after preloading in a drawbead passage

For DC04, the fracture strain decreases with an increasing blank holder pressure. Starting with a drop of the fracture strain of $40 \%$ at $\mathrm{p}_{\mathrm{N}}=2.5 \mathrm{MPa}$, it drops over $70 \%$ for the pressures of $\mathrm{p}_{\mathrm{N}}=5 \mathrm{MPa}$ and $7.5 \mathrm{MPa}$. Similar to the tensile strength, there is no significant change in the values between $5 \mathrm{MPa}$ and $7.5 \mathrm{MPa}$ anymore. For varying the strip velocity under a constant blank holder pressure of $\mathrm{p}_{\mathrm{N}}=5 \mathrm{MPa}$, the fracture strain drops for all variations by about $70 \%$.

When looking at DP800 as a representative for advanced high strength steels, the drop for the fracture strain compared to the initial state is lower than for DC04. For $\mathrm{p}_{\mathrm{N}}=2.5 \mathrm{MPa}$, the fracture strain is lowered by about $20 \%$ compared to the initial specimens. For
$\mathrm{p}_{\mathrm{N}}=5 \mathrm{MPa}$ and $7.5 \mathrm{MPa}$ the reduction is $38 \%$ and $42 \%$. Like DC04, DP800 also does not show any compelling changes for the fracture strain when modifying the strip velocity.

Altogether, it is remarkable that DC04 shows higher modifications for the tensile strength and the fracture strain after drawing the sheet metal through a drawbead geometry. One possible explanation could be the microstructure evolution. According to Nesterova et al. [11], DP800's microstructure evolution of the softer ferrite matrix, is mainly influenced by the hard phase (martensite). This process, of course, is not happening for single phase steels. According to them, DP800 also shows much larger work hardening rates at lower plastic strains, which are correlating pretty well with local internal stresses. Connecting this with the analysed material parameters, it can be a reason for the lower strain values compared to DC04.

Soares et al. [12] also examined the strain hardening behaviour of dual phase steels. He figured out, there is a two-staged strain hardening behaviour for a DP800 steel. Up to a logarithmic strain of 0.025 , the strain hardening exponent $\mathrm{n}$ is increasing rapidly. According to their research, this is due to a lot of mobile dislocations, which are introduced to ferrite by martensitic transformation in the production process. Afterwards, the exponent decreases slightly and comes to a constant value. As a summary, the authors of [12] remark, that this first stage is the most important for the whole forming process and responsible for the fast increase in work hardening of DP steels. This could also be an explanation for the different behaviour of the two steel grades represented by DC04 and DP800.

For the change of the blank holder pressure, a modification could be proved, while the velocity in the investigated area does have ignorable influences on the material parameters. Only for DC04 a small change for the yield strength in Figure 5 can be seen. The higher modifications for DC04 could possibly arise from its higher ability to deform what also can be seen in the initial fracture strain of nearly $\varepsilon_{\mathrm{f}}=45 \%$. DP800, also a cold rolled steel with two different phases, has a lower initial fracture strain. The hardening exponent of DP800, which is about $\mathrm{n}_{\mathrm{DP} 800}=0.27$ and about the double of $\mathrm{n}_{\mathrm{DC} 04}=0.16$, also leads to a higher work hardening and consequently to lower strain levels. Those differences and also a varying texture of the two materials can explain the changes that can be seen.

\section{Summary and Outlook}

First of all, strip drawing tests with a drawbead geometry were performed to replicate stresses and strains in a deep drawing process. The loads were applied to DC04 and DP800 sheet metal in a drawbead passage. The drawing velocity was varied between $\mathrm{v}=10-50 \mathrm{~mm} / \mathrm{s}$ and the blank holder pressure between $\mathrm{p}_{\mathrm{N}}=2.5-7.5 \mathrm{MPa}$. Afterwards, the deformed sheet material was clamped on to the machine bed and the tensile test specimens $\mathrm{A}_{50}$ were cut out by a laser cutting machine. In the next step, those specimens were examined with a conventional 
uniaxial tensile test using an optical measurement system. The preloading process, which is also shown schematically in Figure 1, obviously significantly changes material properties of both sheet metal materials.

The most distinctive findings are:

- The tensile strength TS is increased by about $25 \%$ for DC04 and only by $4 \%$ for DP 800 .

- The fracture strain $\varepsilon_{\mathrm{f}}$ is decreased by over $70 \%$ for DC04 and by $40 \%$ for DP800.

- Increasing the blank holder pressure between $\mathrm{p}_{\mathrm{N}}=2.5-7.5 \mathrm{MPa}$ increases TS in general and decreases $\varepsilon_{\mathrm{f}}$.

- Varying the strip velocity between $\mathrm{v}=10-50 \mathrm{~mm} / \mathrm{s}$ has no significant influence on the tested properties.

It is shown in tensile tests, that drawbeads change the material properties in deep drawing processes. Depending on the material, the tensile strength rises while the fracture strain is decreased. For deep drawing parts, where preloaded metal is part of the final geometry, this needs to be taken into account definitely. Especially for numerical calculations of those parts, it is very important. In the future, it would also be interesting to investigate different drawbead geometries or other materials like aluminium. It is therefore also a need to examine material characteristics for other stress states after preloading like plane strain, shearing or biaxial tests and consider these results in calculations.

For the support in the research project EFB 08/114 (AiF 18328N) the authors would like to thank the European Research Association for Sheet Metal Working e.V. (EFB) as well as the German Federation of Industrial Research Associations „Otto von Guericke“ e.V. (AiF).

The authors would also like to show their gratitude to Ms. Ines Becker, who participated in this experimental study within the scope of her bachelor's thesis.

\section{References}

1. M. Barthau, M. Liewald, H. Christian, J. Phys.: Conf. Ser., 896, 12040, (2017) DOI: 10.1088/1742-6596/896/1/012040

2. H. Mohrbacher, S. Jansto, and F. Siciliano, International Symposium on Niobium Microalloyed Sheet Steel for Automotive Application, (2006)

3. W. Bleck and E. Ratte, Fünftes Industriekolloquium SFB 362 „Fertigen in Feinblech". Abschlusskolloquium Werkstoffe Verfahren - Konzepte, 35-40, (2005)

4. S.-D. Liu, S. Jiang, M. Garnett, 21st Biennial Congress of the International Deep Drawing research Group, 21, 203-212, (2000)

5. H. Schmid, S. Suttner, M. Merklein, 7. WGPJahreskongress Aachen, 37-42, (2017)
6. H. Schmid, S. Suttner, M. Merklein, J. Phys.: Conf. Ser., 896, 12010, (2017) DOI: $10.1088 / 1742-6596 / 896 / 1 / 012010$

7. H. Selcuk Halkaci, M. Turkoz, M. Dilmec, Journal of Materials Processing Technology, 214, 1638-1646, (2014)

DOI:

10.1016/j.jmatprotec.2014.03.008

8. M. Samuel, Journal of Materials Processing Technology, 122, 94-103, (2002) DOI: 10.1016/S0924-0136(01)01233-X

9. E. Silvestre, J. Mendiguren, L. Galdos, E. Sáenz de Argandoña, International Journal of Mechanical Sciences, 101-102, 10-20, (2015) DOI: 10.1016/j.ijmecsci.2015.07.013

10. S. Schreijäg, Microstructure and mechanical behavior of deep drawing DC04 steel at different length scales (KIT Scientific Publishing, Karlsruhe, (2013)

11. E. V. Nesterova, S. Bouvier, B. Bacroix, Materials Characterization, 100, 152-162, (2015) DOI: 10.1016/j.matchar.2014.11.031

12. G. Corrêa Soares, B. Mendonça Gonzalez, L. de Arruda Santos, Materials Science and Engineering: A, 684, 577-585, (2017) DOI: 10.1016/j.msea.2016.12.094 